\title{
Mathematics Textbooks of Primary 1 Used in Singapore: A Multimodal Analysis of Its Intersemiosis
}

\author{
Aylanda Dwi Nugroho \\ English Department, Faculty of Letters, Petra Christian University, \\ Siwalankerto 121-131, Surabaya 60236, East Java, Indonesia \\ e-mail: aylanda@petra.ac.id
}

\begin{abstract}
Mathematical discourse deploys three semiotic resources at the same time - language, symbolism and visual images. It is unique in how it presents mathematical concepts and relations, which are mostly abstract concepts. This paper analyses how these resources collaborate to explain mathematical concepts to Primary 1 students in Singapore. As these students are at the beginning level of learning mathematical concepts, the textbook needs to concretize the abstract mathematical concepts. The data analysis follows Systemic Functional - Multimodal Discourse Analysis or SF-MDA (O'Halloran, 2007). It is concluded that in the deployment of those three semiotic resources, the mathematical speech functions and the mathematical processes have been carefully and effectively selected as seen from the intersemiosis to concretize those abstract mathematical concepts for the young minds.
\end{abstract}

Key words: mathematical discourse, semiotic resources, intersemiosis, systemic functional-multimodal discourse analysis

The meaning-making process in mathematical discourse requires the deployment of language, mathematical symbolism, and visual images. Each of these resources intrasemiotically contributes to the construction of meaning through the meaning potential of that resource, and intersemiotically these resources function to make meaning (O'Halloran, 2007). This functionality varies in accordance with the education level of textbooks. The higher the level of the books, the more words are used but at the same time the more mathematical symbolism and visual images are used, because words alone fail to convey meaning completely. Mathematical symbolism and visual images are congruently deployed to compensate the inadequacy of language (Halliday, 1993) to constitute the intended meaning. Symbolism and images can visually and directly show mathematical concepts and relations that language needs to explain at length. They also help concretize the abstract mathematical concepts and relations which are resulted from linguistic explanation. 
The focus of this paper is to explore the deployment of language, mathematical symbolism and visual images which are used to construct meaning in mathematics textbooks. The analyzed text was taken from "My Pals are Here" Primary 1 Mathematics textbook, and the analysis is based on the Systemic Functional - Multimodal Discourse Analysis (SF-MDA) approach (O’Halloran, 2007).

\section{Systemic-Functional Multimodal Discourse Analysis}

O'Halloran's SF-MDA framework for mathematical discourse (O’Halloran, 2007, p. 27) adopts Halliday's systemic functional grammar (1985, 1994, and 2004 with Matthiessen). For the mathematical symbolism and visual display I refer to O'Halloran's frameworks on the mathematical symbolism and visual display (O’Halloran, 1999, pp. 12-13; 16-17) which are presented in Tables 1, 2, and 3 respectively.

Table 1. SF-MDA Framework for Mathematical Discourse (from O’Halloran, 2007)

\begin{tabular}{|c|c|c|c|c|}
\hline \multicolumn{5}{|c|}{ IDEOLOGY } \\
\hline \multicolumn{5}{|c|}{ GENERIC MIX } \\
\hline \multicolumn{5}{|c|}{ REGISTERIAL MIX } \\
\hline \multirow{6}{*}{ CONTENT } & \multicolumn{4}{|c|}{$\begin{array}{lcl} & \text { INTERSEMIOSIS } \\
\text { MINI-GENRES, ITEMS AND COMPONENTS }\end{array}$} \\
\hline & LANGUAGE & $\begin{array}{l}\text { MATHEMATICAL } \\
\text { SYMBOLISM }\end{array}$ & $\begin{array}{l}\text { MATHEMATICAL } \\
\text { VISUAL IMAGES }\end{array}$ & OTHER \\
\hline & \multicolumn{4}{|c|}{$\begin{array}{c}\text { INTERSEMIOSIS } \\
\text { Discourse Semantics }\end{array}$} \\
\hline & Discourse & $\begin{array}{l}\text { Inter-statemental } \\
\text { Relations }\end{array}$ & $\begin{array}{l}\text { Inter-visual } \\
\text { Relations Work }\end{array}$ & \\
\hline & \multicolumn{4}{|c|}{$\begin{array}{l}\text { INTERSEMIOSIS } \\
\text { Grammar }\end{array}$} \\
\hline & $\begin{array}{l}\text { Clause Complex } \\
\text { Clause } \\
\text { Word Gr/Phrase } \\
\text { Word }\end{array}$ & \begin{tabular}{|l|} 
Statements \\
Clause \\
Expression \\
Element
\end{tabular} & \begin{tabular}{|l|} 
Episode \\
Figure \\
Part
\end{tabular} & \\
\hline \multirow[t]{2}{*}{ DISPLAY } & \multicolumn{4}{|c|}{$4+\begin{array}{c}\text { INTERSEMIOSIS } \\
\text { Materiality }\end{array}$} \\
\hline & \multicolumn{4}{|c|}{ Graphology, Typography and Graphics } \\
\hline
\end{tabular}




\section{The Generic and Registerial Mix of Math Discourse}

Mathematical discourse is comprised of several genres or mini genres (O’Halloran 2007, p. 86), such as explanation, laws, theorems, definitions, stories, dialogs, questions, problem demonstration, and solutions. Each of these takes different registers, tenors, and mode selections. Within these genres, there are a number of items, and within each item there are a number of smaller multimodal components. For example, the genre of problem demonstration consists of a problem item and a problem solution. The problem item consists of only one component (the question), and the problem solution item may consist of an explanation, a table, a graph, question answers, and a note / remark. O'Halloran further said that “... the textual organization and the consistent nature of the interpersonal relations permit the ideation content of mathematical discourse to be foregrounded “ (O’Halloran, 2007, p. 90).

\section{$\underline{\text { Intersemiosis }}$}

Intersemiosis in mathematical texts is operated through several mechanisms as O’Halloran (2007, pp. 92-94) proposed. The first is Semiotic Cohesion, in which within and across the mini genres, items and components, as well as across the three semiotic resources, cocontextualizing processes always come into play. In this way the whole text becomes coherent. The second is Semiotic Adoption. It is the process of re-contextualization by the use of one semiotic system which is incorporated into another semiotic system. The third intersemiosis is Semiotic Mixing, whose mechanism involves the mixing of system choices from two or more semiotic resources. In this graph all three semiotic resources are used. The fourth is Juxtaposition and Spatiality. The arrangement of the mini genres, items, components and constituent elements are in such a way that facilitates semiosis, for example, the use of spatial distinctness and centering are effective to allow an important element like a symbolic equation to be foregrounded as new and important information. The fifth intersemiosis is Semiotic Transition. This involves system choices from one or more semiotic resources to another or other semiotic resources to mark the shift from one mini-genre, item, and component to another (macro transitions ) as well as the shift within the item (micro transitions ). The last is Semiotic Metaphor, which involves the 
shift from certain functional status of elements to the new elements. These intersemiosis mechanisms will be made clear in the analysis.

\section{A framework for a Systemic Functional Grammar of Mathematical Symbolism}

In the systemic functional grammar developed by Halliday (1994), the system that constitutes the lexicogrammar of English consists of the Ideational meaning, which is further divided into Experiential and Logical metafunctions, then the Interpersonal and the Textual metafunctions. These metafunctions are at the rank of clause although Halliday also describes other systems at the rank of word, phrase, and clause complex. The semantic categories of process types are: processes of event or action (Material); processes of thinking, feeling and perceiving (Mental); processes of saying (Verbal); processes of being and having (Relational); processes of behaving (Behavioural); and processes of existing (Existential).

Compared to that of natural language, the Experiential meaning of mathematical symbolism is limited to processes which are mostly Relational-Identifying, and Operative processes, which are needed in mathematical symbolism (O’Halloran, 2003). Operative processes are defined as "actions performed by human agents on mathematical participants such as numbers, and later, variable and 'abstract' qualities...'(O’Halloran, 2003, p. 91). Unlike the linguistic process types, in mathematical symbolic statements, Medium can be more than one and all have equivalent status.

The Interpersonal meaning of mathematical symbolism is mostly statements and commands and is realized through the deployment of both linguistic and symbolic elements, for example, "Add 5 to 10". Interpersonal meaning is also realized through the use of contrasts in font and size. The steady nature of mathematical symbolic texts can maintain a stable interpersonal relation with the reader (O’Halloran, 2007, p. 84).

In mathematical symbolic texts there is a conventional order of operations which is indicated by the use of types of brackets, conventional spatial presentation, labeling, and repetition of reference to show cohesion. In general, textually, mathematical symbolic texts are neat and compact.

The functions and systems chart for the analysis of mathematical symbolism is presented in Table 2. 
Table 2. SF-MDA Framework for Math Symbolism (from O’Halloran, 1999)

\begin{tabular}{ll}
\hline & MATHEMATICAL SYMBOLISM \\
\hline CONTENT & Discourse Semantics \\
& Inter-statemental Relations \\
& Grammar \\
& Statement (Clause complex) \\
& Clause \\
& Expression \\
& Element \\
DISPLAY & Typography/ Graphology \\
\hline
\end{tabular}

\section{A Framework for Systemic Functional Grammar of Mathematical Visual Display}

The framework presented in Table 3 was developed by O'Halloran (1999) using O’Toole's (1994) systemic functional model in his book The Language of Displayed Art. In mathematical symbolic texts, the visual displays that are usually in the form of graphs or diagrams are important in displaying trends and patterns which cannot be satisfactorily displayed in mathematical symbolically expressed relations (Lemke, 1998 in O’Halloran, 1999, p. 15). O’Halloran further asserts that "in combination with the verbal discourse and symbolic statements, the visual displays function to realize ‘truth' of mathematics” (1999, p. 18). Viewer's gaze is developed through the use of labels, titles, arrows, and others. Unlike the work of arts that develop individual style for the sake of uniqueness, mathematics texts use features that are conventionalized. This is very important for quick reference and for avoiding ambiguity.

Table 3. SF-MDA Framework for Visual Images (from O'Halloran, 1999, 2005)

\begin{tabular}{ll}
\hline MATHEMATICAL VISUAL IMAGES \\
\hline CONTENT & Discourse Semantics \\
& Inter-Visual Relations \\
& Work / Genre \\
& Grammar \\
& Episode \\
& Figure \\
& PartS \\
DISPLAY & Graphics \\
\hline
\end{tabular}




\section{METHODS}

\section{Data Collection and Analysis}

The data were taken from a mathematics textbook widely used for primary school students in Singapore, My Pals are Here. It was written by Dr. Fong Ho Kheong, Chelvi Ramakrishnan and Lau Pui Wah, and published by Marshall Cavendish Education, Singapore. Chapter 12, entitled Numbers to 40 was specifically chosen as the data of this paper because at this stage the learners are believed to be in the middle of beginning level and thus have relatively learned the very beginning stage of counting and addition from 1 to 30 .

Each page of this chapter was analyzed in terms of which of the three semiotic resources, ie. the language, the pictures and the mathematical symbols, were selected. Further, I analyzed how these resources were deployed by the textbook writers to explain the mathematical concepts of addition to 40. This stage includes the analysis of the ideational, interpersonal and textual meanings of those resources and their intersemiosis. Due to limited space, this paper concentrates on the Display and Content strata.

\section{FINDINGS AND DISCUSSION}

\section{The Generic and Registerial Mix of the Text}

Each chapter consists of several mini-genres. They are Problem Demonstration, Problem Questions and Problem Solution, and they are presented in very guided and scaffolded steps moving from the easiest or most familiar to the new or more difficult concepts.

The Problem Demonstration explains abstract concepts such as 'amount' using concrete objects (in this case, pieces of Lego) in exact numbers. From this, the text moves step-by-step to the Problem Questions and Problem Solution in a very careful and consistent way. In every step, the text linguistically invites the readers to participate or interact in the process. In Chapter 12 entitled Numbers to 40 as given above, in the problem demonstration part, the math problem is presented through a stepby-step instruction complemented with pictures of real objects in real amounts. 


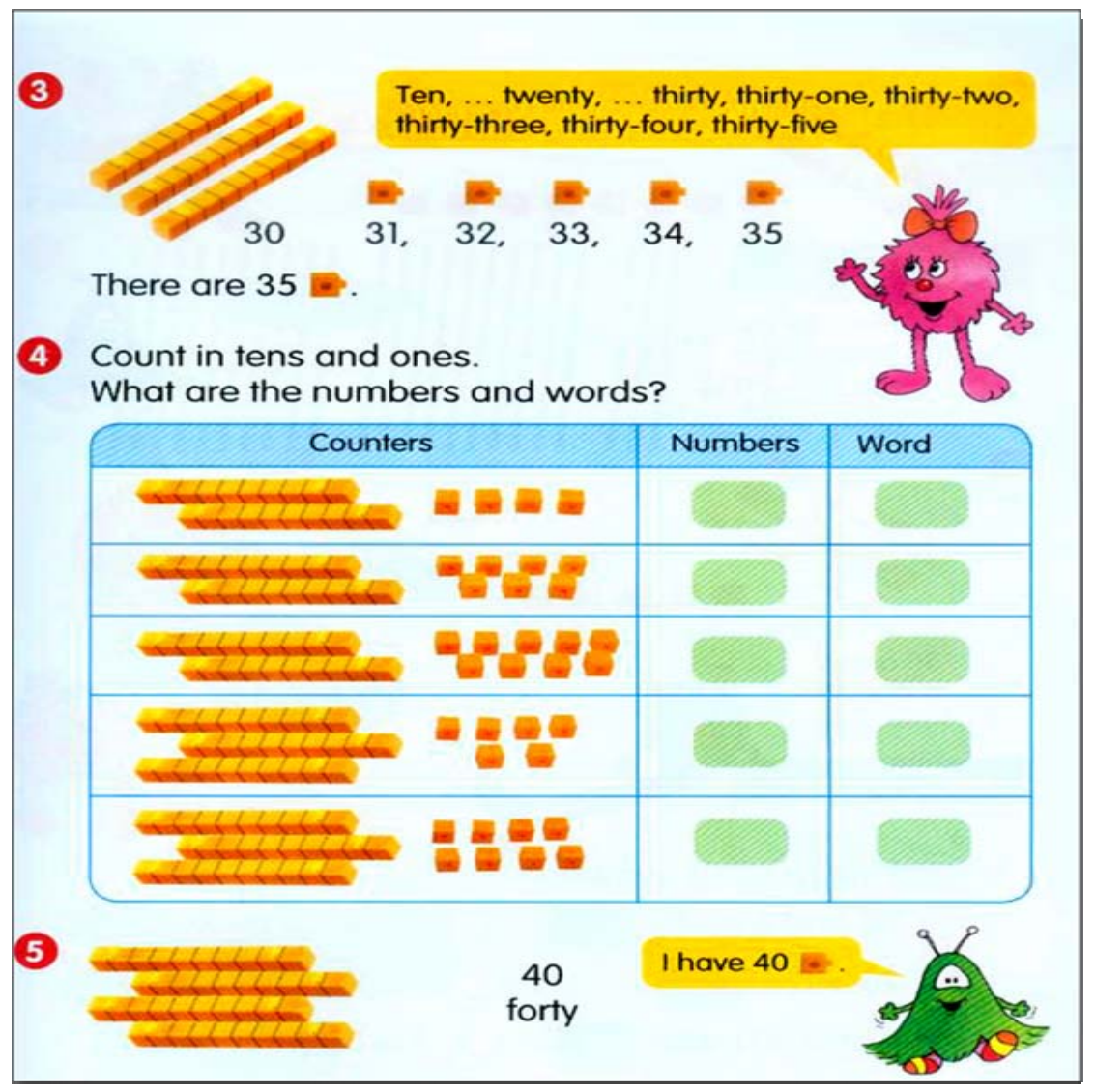

Figure 1. Primary 1, p. 27

The Problem Demonstration explains abstract concepts such as 'amount' using concrete objects (in this case, pieces of Lego) in exact numbers. From this, the text moves step-by-step to the Problem Questions and Problem Solution in a very careful and consistent way. In every step, the text linguistically invites the readers to participate or interact in the process. In Chapter 12 entitled as given above, in the problem demonstration part, the math problem is presented through a step-by-step instruction complemented with pictures of real objects in real amounts. The instructions on each red-circled number lead the students/readers to grasp the concept of addition to 40 using the students' experience in addition within 10, 20 and 30, which they have learned in the previous chapters. This can be seen from Figure 1, in which the text shows that the tens are already three, thus thirty, and then it directs the students to further count the ones one by one until they reach forty (at the bottom of the page). 
However, the boundaries among those mini-genres are not explicitly marked, because, for example, in the Problem Demonstration, the text involves the readers to answer some questions as well, such as filling in some blanks. As an example, on the way to explain the quantity of " 40 " (forty), the text asks the readers to fill in the green boxes (red-circled number 4 in Figure 1). Rather, the text moves slowly to the Problem and Solution, as it can be seen in Figure 2.

(5) Which number is greater? Which number is smaller?

Are the tens equal?

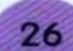

32

tens is greater

than
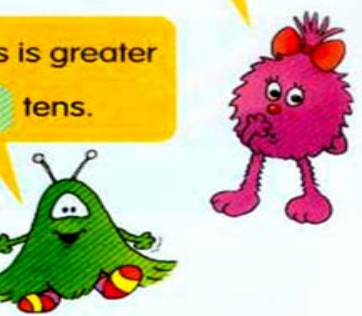

So,

is greater than

is smaller than
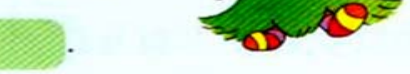

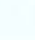

6) Which number is greater? Which number is smaller?

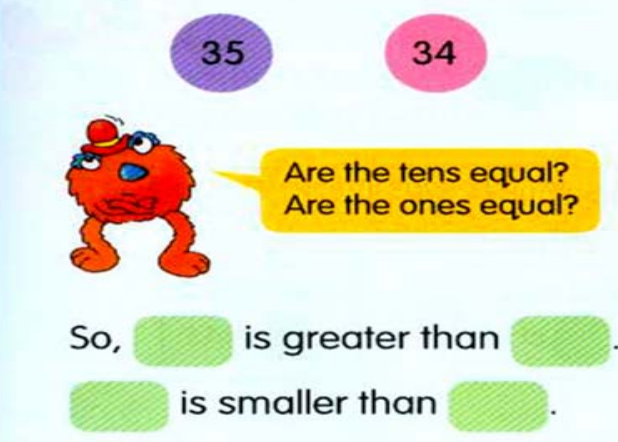

Figure 2. Primary 1, p. 33

Although it is not explicitly stated, the mini-genres still consist of the standard mathematical Items and Components, such as Items the Problem with its Components: Problem Context, Table and Questions; and the Solution with its Components: Numbers, Steps of Solution and Question Answers. Textually, the layout is somewhat free yet consistently started from the left margin and going down chronologically. It looks free because 
of the insertion of some cartoon characters on any corner of every page. Interpersonally, on the other hand, the statements and commands are straightly put on the left margin. Ideationally, the Questions and the Question Answers also always start from the left margin.

At the Display stratum, the spatial positioning, color, font style and size also work intersemiotically to generate mathematical understanding of the young learners. All statements, commands and questions are started from the left. The number of steps is circled in red (in the original copy) and the numbers being discussed are in colored circles. Additional questions are put in colored boxes or speech bubbles and many others. Figure 3 is an example.

(3) Compare 28 and 31.

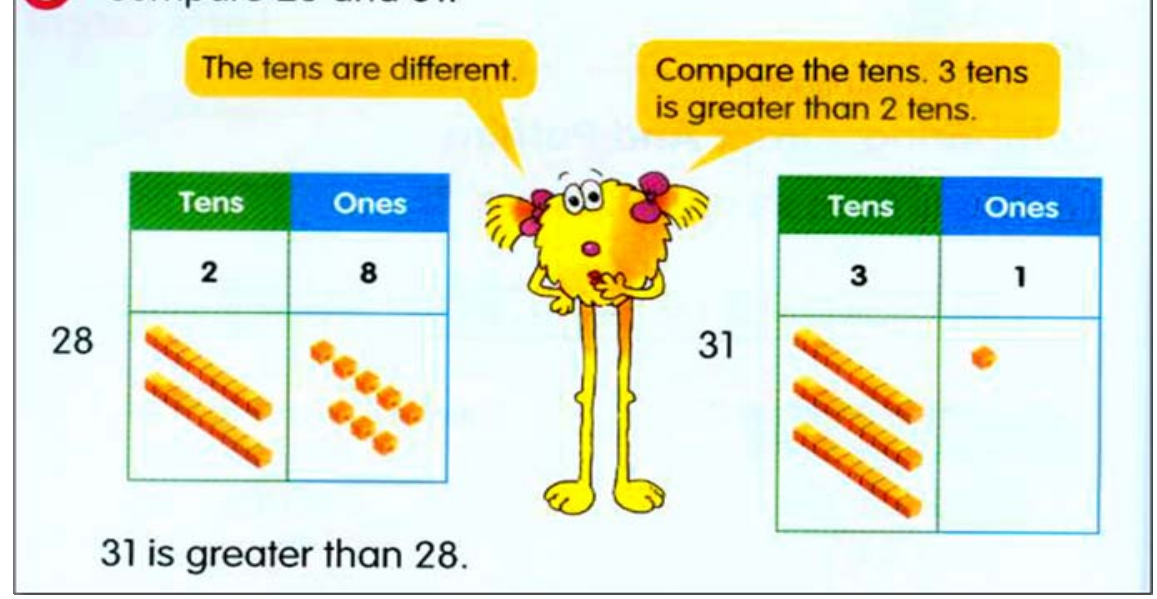

Figure 3. Primary 1, p. 32

\section{The Linguistic Aspects of the Text}

The linguistic elements of the beginning part of chapter consist of instructions of small interrelated steps to teach the students how to solve the problem. Imperative sentences are used very often from the start, such as "Count the blocks", "Make tens with the [Lego pieces] and count.", "Find the missing number". These imperative sentences following the section numbers $(1,2,3$, etc) suggest very strongly that the book or the writers of the book are speaking to the students as the readers who should follow the steps in solving the mathematical problems in the book. The writers 
suggest an authoritative position in instructing the students in doing the exercises. This is in line with what O Halloran (2007, p. 84) stated that "the tenor remains constant as unmodulated commands are issued and information is given". This Action Command speech function with its imperative mood makes it very clear that the focus is not on the language but on the mathematical symbols and processes.

The strict commands on every step in the mathematical process, however, are softened by the presence of the cartoon characters, who definitely are included here to be children-friendly agents to accompany the students in learning this somewhat 'scary subject'. These cartoon characters always re-word or re-phrase the "authority's commands" into more detailed and friendly sentences, sometimes in imperative (which sounds more as directions than commands), declarative or interrogative sentences. For example, the command in number 4 "Compare 34 and 37" in Figure 4 is 'softened' by the declarative sentences of Noogol and the solidarity marker "we". Although afterwards he uses also the imperative 'compare', the pressure is not as strong.

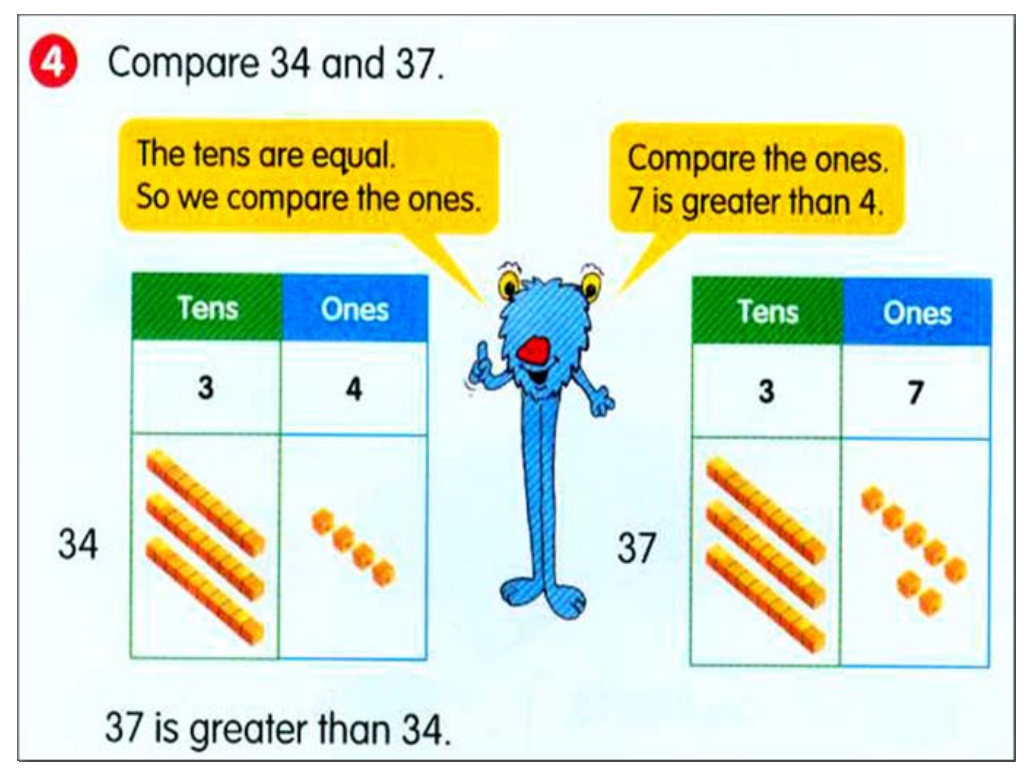

Figure 4. Primary 1, p. 32

It is interesting to observe that Declarative sentences are used first in the middle part of the chapter, as it can be seen from page 31 in Figure 5 (note: Chapter 12 starts on page 26). Comparing the other chapters in this 
textbook with this chapter, it can be seen that Declarative sentences are used in the middle part as the difficulty level increases. These are used to present a problem in which the students should apply what they have previously learned in the Problem Demonstration Mini-Genre.

Interrogative sentences, on the other hand, are used much later in the middle of the chapter as part of the Question Component of Items Problem and Solution. Transition or connecting words showing stages are also often used. For example, on page 67 as seen below, the text explicitly uses "First, subtract the tens.", "Then, add the result to the ones."

\section{Comparing, Order And Pattern}

(1) This is Googol's counting tape.

$$
\begin{array}{|l|l|l|l|l|l|l|l|l|l|l|l|l|l|l|}
\hline \multicolumn{10}{c|}{2 \text { more }} & \multicolumn{10}{c|}{2 \text { less }} \\
\hline 26 & 27 & 28 & 29 & 30 & 31 & 32 & 33 & 34 & 35 & 36 & 37 & 38 & 39 & 40 \\
\hline
\end{array}
$$

Count on from 27.

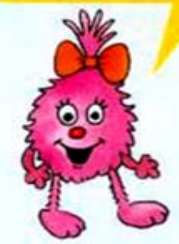

29 is 2 more than 27.

29 is greater than 27 .
Count backwards from 38 .

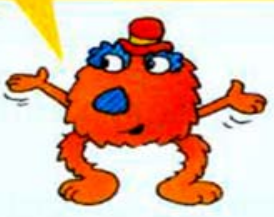

36 is 2 less than 38 . 36 is smaller than 38 .

2 This picture shows part of Googol's calendar.

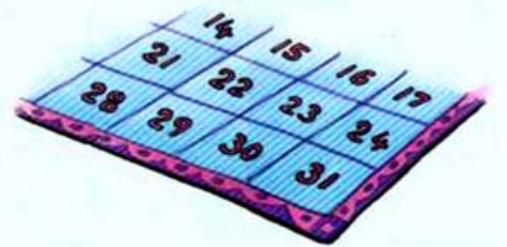

is 2 more than 22 .

is 3 less than 31 . is greater than 22 . is smaller than 31 .

Figure 5. Primary 1, p. 31 


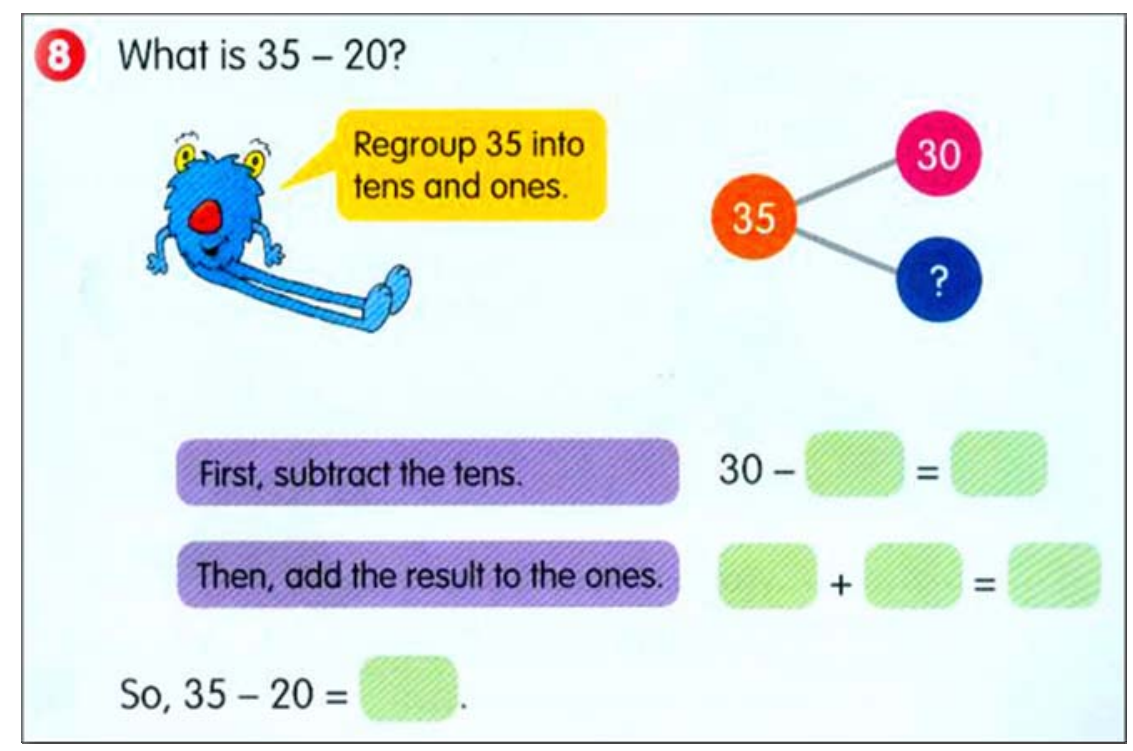

Figure 6. Primary 1, p. 67

Some questions are used more towards the end of the chapter as a reflection or self-testing about the previous problem discussed in the middle part of the chapter. For example, the questions "Why is it the smallest number?" and "Why is 35 greater than 33?" in the example in Figure 7.

One principle in mathematical discourse is that the language accompanying the mathematical symbols and visual images should be economical. However, for young learner, the mathematical concepts must be elaborated step-by-step in short and simple language. This has been achieved well by this book. At the Expression stratum, it can be seen that the font size is relatively big, the font style is relatively simple (Century Gothic), and there are relatively not too many words on one page. Also, young students learning mathematics will always be accompanied by adult tutors, teachers or parents who obviously will further explain, direct, ask and confirm to fill the gaps among what is written in the book. Thus, the minimum language present in Primary 1 Mathematics textbook is acceptable.

The language patterns have followed a careful sequential manner in a way that Imperative sentences start the chapter in the Problem Demonstration Mini-Genre, and Declarative sentences follow at the end of Problem Demonstration. Interrogative sentences Yes/No start the Problem 
Context Mini-Genre and followed by Imperative sentences to direct the Solution and the chapter is closed with Interrogative Open-ended sentences as a reflection of the whole mathematical process of the section. An example of Interrogative Open-ended sentences can be seen in Figure 7.

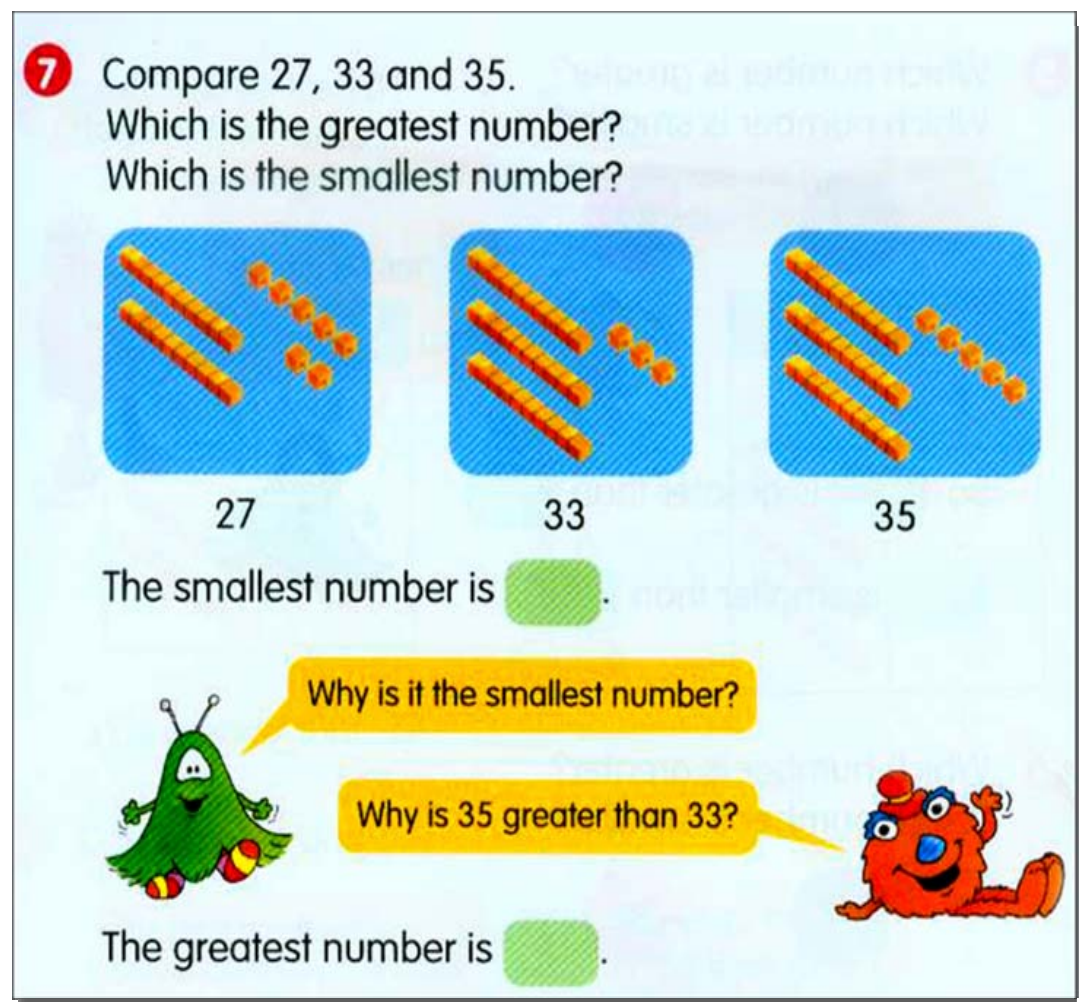

Figure 7. Primary 1, p. 34

At the Content stratum, obviously it can be seen that the highest level of the language of this mathematical textbook is mostly Clause with short and simple Imperative, Declarative and Interrogative sentences. Clause Complex level is not found, while Discourse Relations occur very rarely and only towards the end of the book to sum up the mathematical processes having been discussed. The example is shown in Figure 8.

In relation to the subject topic, the noun groups most often consists of common and popular nouns, such as "eggs", "buttons", "balls", "cakes" and "toys". So do the verb groups with "count", "buy", "have”, give” and "eat". The adjective groups use more comparative adjectives such as "more than", "less than", "greater than”, and "smaller than". 


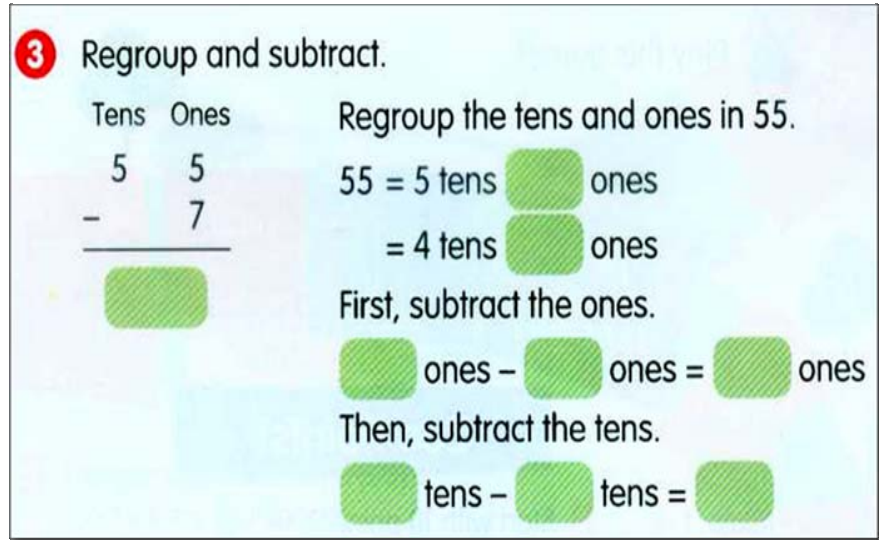

Figure 8. Primary 1, p. 117

\section{The Math Symbolism}

As the math problems at Primary 1 level are still simple, the symbols that are used in the book are also simple. These only include "+” plus , “-“ minus, “=” equal, and " $\mathrm{x}$ ” multiply. Following O'Halloran’s framework, the symbols are maximum at Clause level with Relational Identifying process "=". The Participants are the same with the Elements, that is, numbers only, without italicized letters indicating certain values. No rankshifted Expression is found. Another symbolism used is that of 'number bonds' and layered addition and subtraction. Figure 9 is the example.

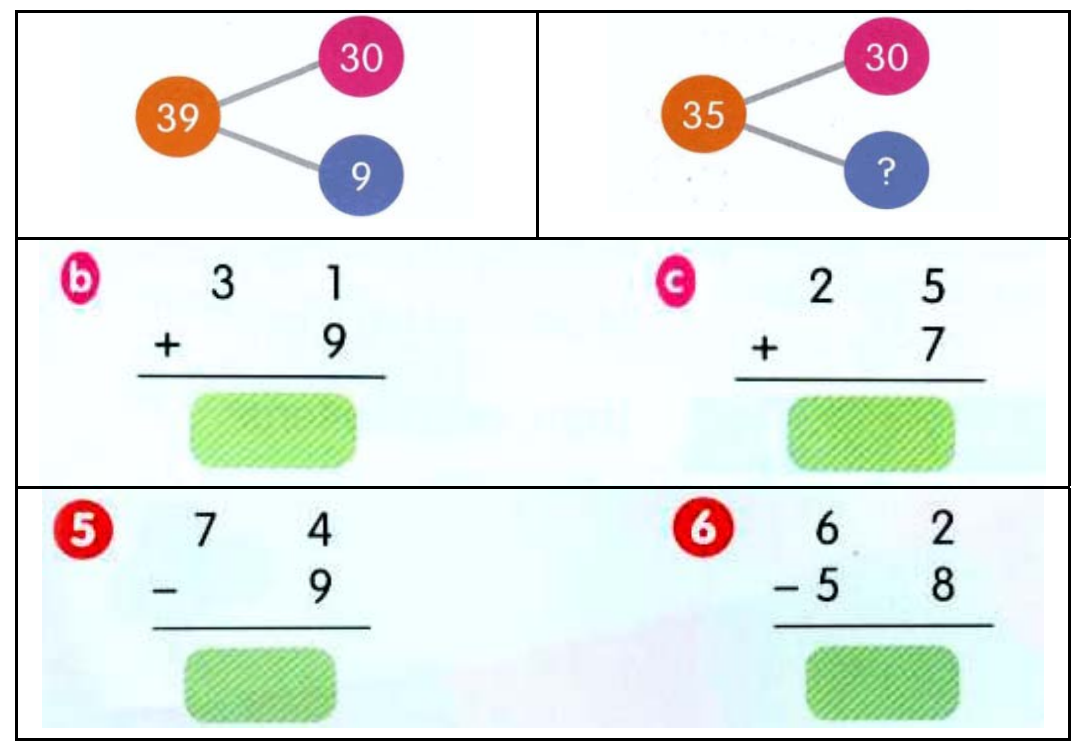

Figure 9. Primary 1, pp. 44, 63, 117 


\section{The Visual Images}

Because the mathematical concepts and processes taught in Primary 1 are still simple, the visual images that are used are not in the forms of abstract graphs, statistical graphs or geometrical diagrams. On the other hand, the visual images in this textbook include pictures of real objects and cartoon characters which function intersemiotically well with the language and the math symbols. The visual images of Primary 1 Math textbook are very rich in colors and consist of cartoon characters, speech bubbles to focus on, photos and pictures of real objects, colored tables, pictograms and others. For example, the following cartoon characters are introduced right from the beginning, for which the book is named, My Pals are Here.

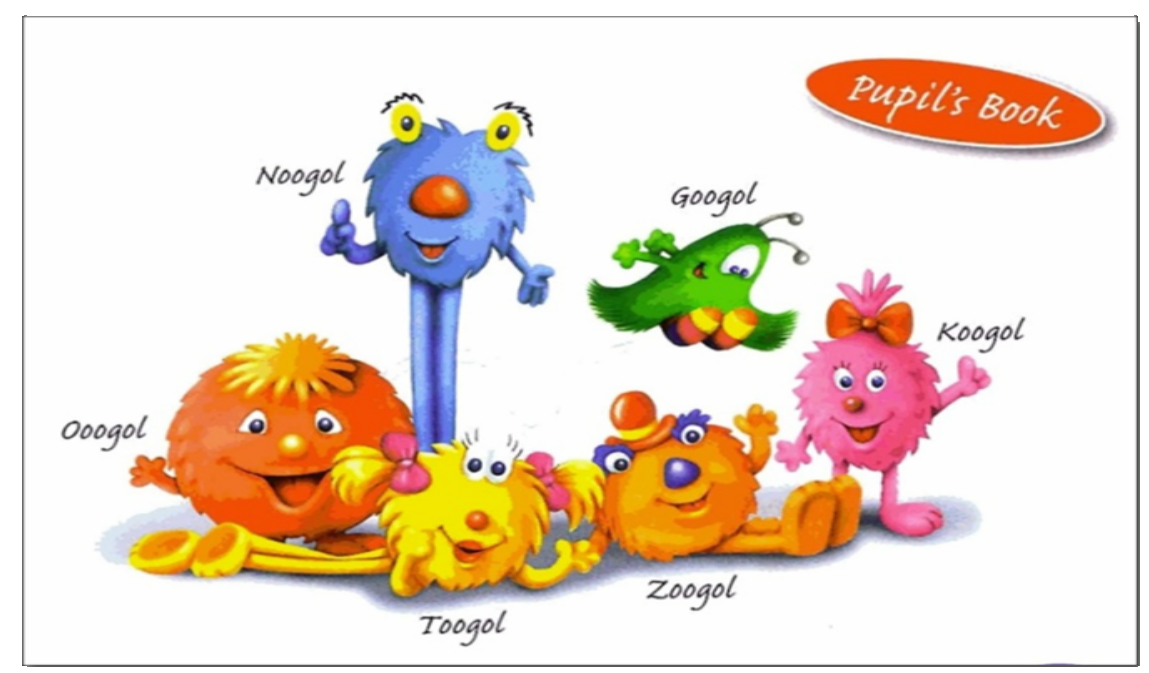

Figure 10. Primary 1, cover page

As it has been shown earlier, some of these characters are always present on every page, communicating to the students and mediating the communication between the 'authors' and the students. They project not only what the authors want to say to the readers but also as the Sayers of what they want to say to the readers.

As O'Halloran (2007, p. 85) said that, “... mathematics image makes visible the relationship which is symbolically encoded ....”, the visual images of Primary 1 Math textbook are also used to fulfill this function. Although they are depicted and utilized in a very 
simple way, this strategy is very helpful for the young minds to grasp the abstract concepts of mathematics. For example the pictures of real objects in real amount in Figures 11 are used to make abstract concept of 'amount' into concrete concept because then the students can count the amount of those familiar objects in their world.

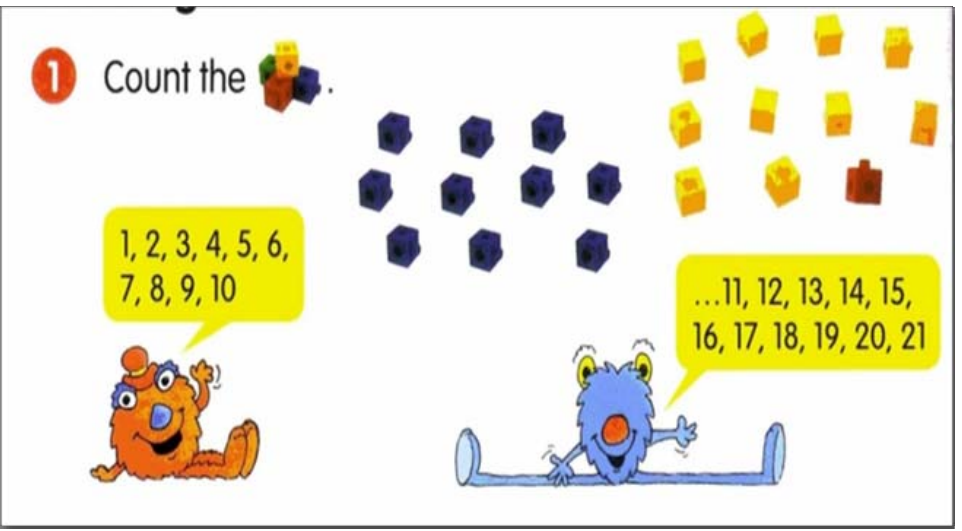

Figure 11a. Primary 1, p. 26

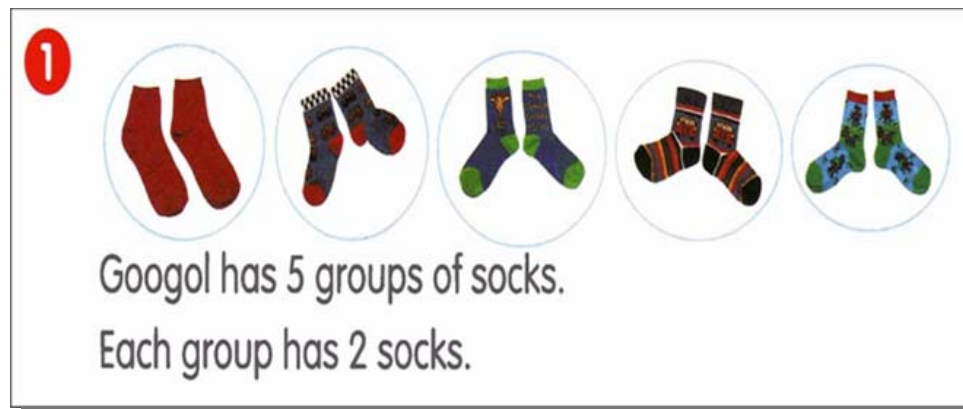

Figure 11b. Primary 1, p. 73

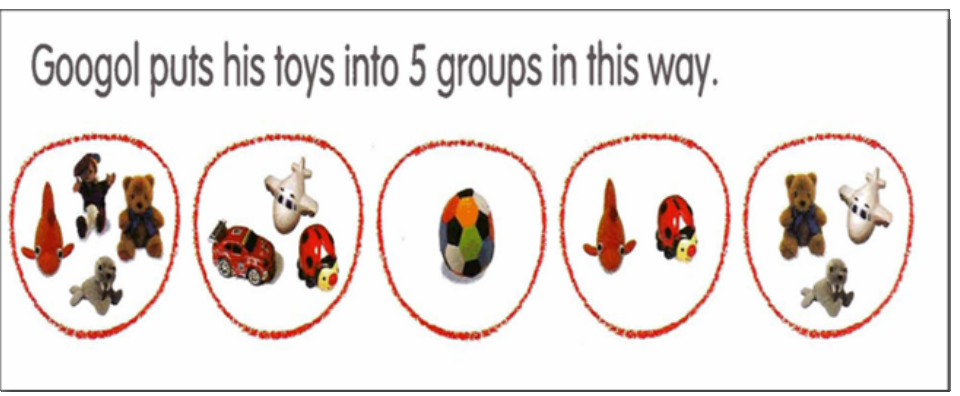

Figure 11c. Primary 1, p. 73 


\section{The Intersemiosis of the Linguistic, Symbolical and Visual Aspects}

What is important in the analysis of the multimodality of mathematical textbook is the intersemiosis of the three semiotic resources, which are not separable and thus cannot be treated separately. Only for the convenience of analysis are these resources theoretically separated (O'Halloran, 2007, p. 79). This fact is significantly strengthened in math textbook for Primary 1 . The language, symbols and visual images of this math textbook are used to complement each other in explaining the simple mathematical concepts. The intersemiotic processes which are mostly involved in this text are Semantic Cohesion, Semantic Adoption and Juxtaposition and Spatiality.

Semiotic Cohesion can be seen very clearly from the repetition of language, symbols and visual images which are co-contextualized to explain certain mathematical processes. For example, in Figure 12, the Lego blocks in ones and tens are repeated several times, and these are complemented with Arabic numbers " $1,2,3,4, \ldots, 21$ ", and numbers in words, "ten, twenty, twenty-one". When the mathematical problem needs several steps in solving it, the text deploys Transition/connecting words, such as "First,...", "Then, ...”. This can be seen from Figure 8 previously.

The second intersemiosis is Semiotic Adoption, in which the symbols occur very often in the language or sentence. To understand the concept, the mathematical process should be put in words so that the learners consciously understand the relation depicted in the symbols and later become able to "read" the equation correctly. For Primary 1 students, the textbook use this when a new mathematical process is introduced. Figure 13 is the example when Multiplication is introduced for the first time.

The third important intersemiosis found in the math textbook of Primary 1 is Juxtaposition and Spatiality. From all of the above examples taken from the book has shown how the mini-genres, items, components and elements of all semiotic resources have been arranged in such a way to facilitate intersemiosis. The leftmargin commands in red-circled numbers, the top-to-down order of chronological processes, the letters and numbers in big 
fonts, the colored tables, and the cartoon characters with their communicative and friendly talks in colored speech bubbles are all effectively deployed to help the learners understand these early mathematical concepts and processes.

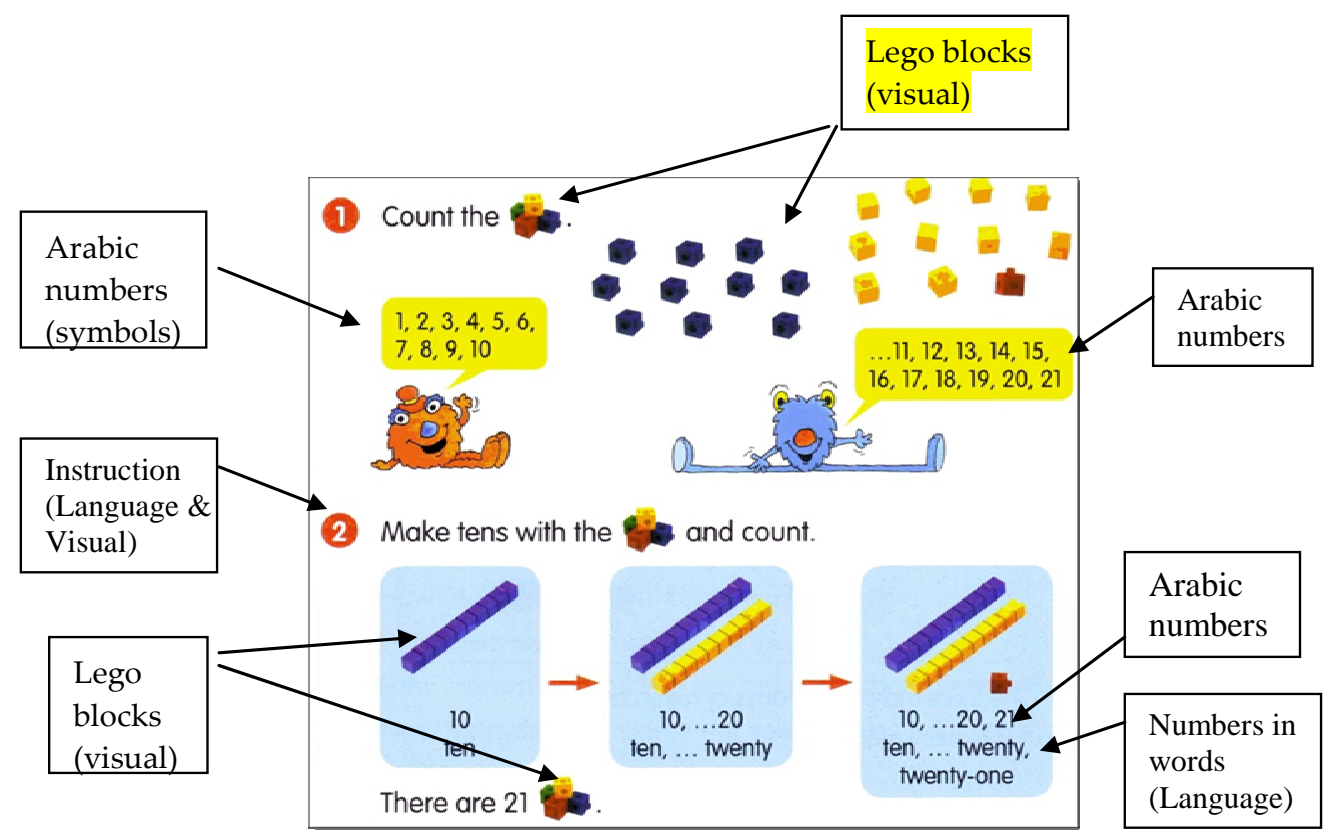

Figure 12. Primary 1, p. 26

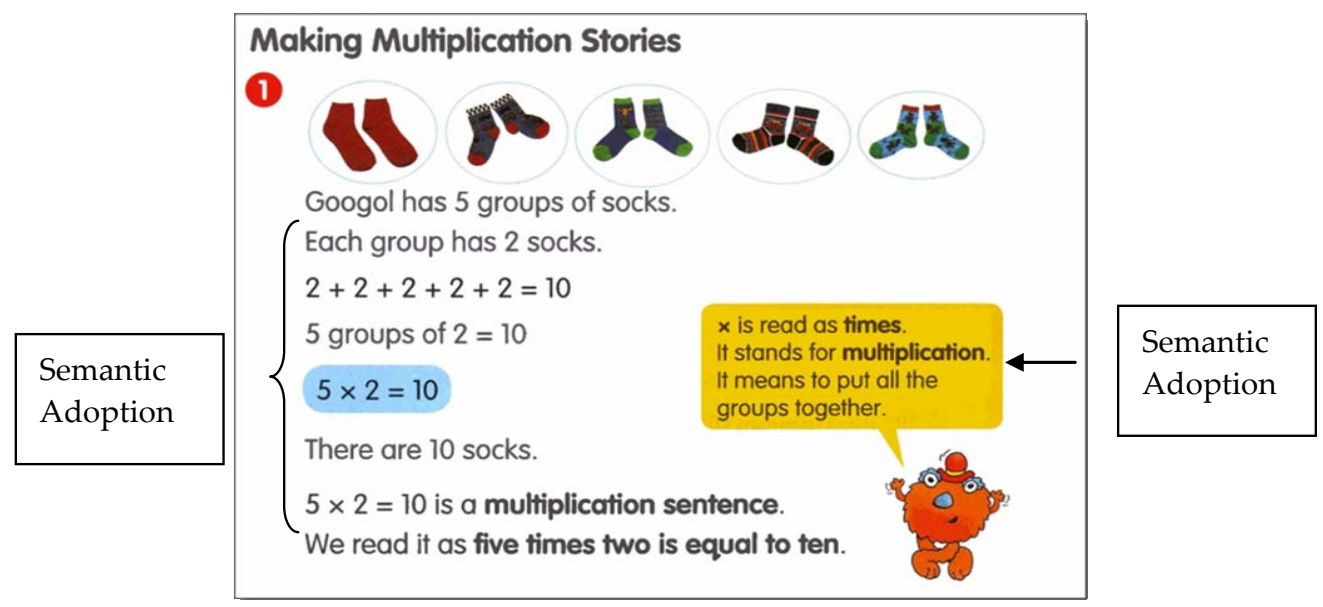

Figure 13. Primary 1, p. 73 
The other intersemiosis mechanisms, that is, Semiotic Mixing, Semiotic Transition and Semantic Metaphor are not found in this textbook due to the nature of simple mathematical problems for Primary 1.

\section{CONCLUSION}

The intersemiosis of the three semiotic resources involved in mathematical discourse has proven to be indispensible, especially for young learners whose mental processes mostly involve only concrete and factual materiality. The visual images convert abstract concepts, which are difficult to grasp when put in language, into 'tangible' objects. Young learners may find the language of math difficult because they are at the same time still learning to spell and read words. The simple mathematical symbolism has assisted them in 'reading' mathematical relations such as addition or subtraction. The linguistic elements in the math discourse are most often used to direct mental and action processes of the learners to further practice the math formula. Although adult assistance is still needed to word out the instructions and directions, the deployment of the three resources together has concretized those abstract concepts. This way has set up a strong and deep foundation for those young minds to understand basic mathematical concepts and more complicated math concepts.

Reversing the analysis process into synthesis process, we can put this intersemiosis of semiotic resources into consideration when writing mathematics or science textbooks because one semiotic resource can strengthen and support other resources to realize the meaning potential of such discourses.

\section{REFERENCES}

Halliday, M. A. K. (1985). An introduction to functional grammar. London: Edward Arnold.

Halliday, M. A. K. (1993). Some grammatical problems in scientific English. In M. A. K. Halliday, \& J. R. Martin (Eds.), Writing science: Literacy and discursive power (pp. 69-85). London: Falmer.

Halliday, M. A. K. (1994). An introduction to functional grammar ( $2^{\text {nd }}$ ed.). London: Arnold.

Halliday, M. A. K., \& Matthiessen, C. (2004). An introduction to functional grammar ( $3^{\text {rd }}$ ed.). London: Arnold. 
O’Halloran, K. L. (1999). Towards a systemic functional analysis of multisemiotic mathematics texts. Semiotica, 124(1/2), 1-29.

O’Halloran, K. L. (2005). Mathematical discourse: Language, symbolism and visual images. London and New York: Continuum.

O’Halloran, K. L. (2007). Systemic Functional Multimodal Discourse Analysis (SF-MDA) approach to mathematics, grammar and literacy. In A. McCabe, M. O’Donnell, \& R. Whittaker (Eds.), Advances in language and education (pp 77-102). London: Continuum.

O’Halloran, K. L. (2007). Mathematical and scientific forms of knowledge: A systemic functional multimodal grammatical approach. In F. Christie, \& J. R. Martin (Eds.), Language, knowledge and pedagogy: Functional linguistics and sociological perspectives (pp 205-236). London: Continuum.

Pimm, D. (1987). Speaking mathematically: Communication in mathematics classrooms. London: Routledge and Kegan Paul. 